\title{
Experiences With the Dutch Working Party on Antibiotic Policy (SWAB)
}

\section{J M Prins (j.m.prins@amc.nl) ${ }^{1}$, J E Degener², A J de Neeling ${ }^{3}$, I C Gyssens ${ }^{4,5}$, the SWAB board}

1. Academic Medical Center, Department of Internal Medicine, Division of Infectious Diseases, Tropical Medicine and AIDS, Amsterdam, the Netherlands

2. Department of Medical Microbiology, University Medical Centre Groningen, Groningen, the Netherlands

3. Laboratory for Infectious Diseases and Perinatal Screening (LIS), National Institute for Public Health and the Environment (RIVM), Bilthoven, the Netherlands

4. Infectious Diseases Section, Department of Medicine, Nijmegen University Center for Infectious Diseases (NUCI), Radboud University Nijmegen, Nijmegen, the Netherlands

5. Department of Medical Microbiology and Infectious Diseases Canisius Wilhelmina Hospital, Nijmegen, the Netherlands

\begin{abstract}
The Dutch Working Party on Antibiotic Policy (Stichting Werkgroep AntibioticaBeleid, SWAB) was founded in 1996 as an initiative of the Society for Infectious Diseases, the Dutch Society for Medical Microbiology, and the Dutch Association of Hospital Pharmacists. Its primary goal is to contribute to the containment of antimicrobial resistance and the expanding costs incurred for the use of antibiotics. SWAB is the Intersectoral Coordinating Mechanism (ICM) for the Netherlands, and it is at present the National Antimicrobial Resistance (AMR) Focal Point. It coordinates the national surveillance of antibiotic resistance, in collaboration with the National Institute for Public Health and the Environment (RIVM), coordinates the surveillance of the use of antibiotics, and runs a guideline development programme. Information about consumption of antimicrobial agents and antimicrobial resistance among medically important bacteria is presented annually in NethMap. Over the past decade, outpatient consumption of antibiotics has risen only slightly, but in the hospital setting there was an overall significant increase in antibiotic use, due mainly to the steady reduction in the average length of patient hospital stays. In 2006 we introduced our electronic national antibiotic guide 'SWAB-ID' for the antibiotic treatment and prophylaxis of common infectious diseases in hospitals.
\end{abstract}

\section{Background}

The Dutch Working Party on Antibiotic Policy (Stichting Werkgroep Antibiotica Beleid, SWAB) was founded in 1996 as an initiative of the Society for Infectious Diseases (VIZ), the Dutch Society for Medical Microbiology (NVMM), and the Dutch Association of Hospital Pharmacists (NVZA). Its primary goal is to contribute to the containment of antimicrobial resistance and the expanding costs incurred for the use of antibiotics. This was to be achieved by optimising the use of antibiotics through guideline development, education, and surveillance of antibiotic use and resistance. Following advice by the Dutch Advisory Council on Health Research in 2000 on the containment of Antibiotic Resistance, in 2001 SWAB was appointed by the Dutch Ministry of Health, Welfare and Sports to coordinate the national surveillance of antibiotic resistance, in collaboration with the National Institute for Public Health and the Environment (RIVM) (currently: the Centre for Infectious Disease Control Netherlands, CiB), and to coordinate the surveillance of the use of antibiotics. Structural funds were provided, also for the guideline development programme. Finally, a platform with the Veterinary Antibiotic Usage and Resistance Surveillance Working Group (VANTURES) was created. When the "Council Recommendation on the prudent use of antimicrobial agents in human medicine" (2002/77/EC) [1] was issued, SWAB became the Intersectoral Coordinating Mechanism (ICM) for the Netherlands, and it is at present the National AMR Focal Point.

NethMap - the annual report on antimicrobial use and resistance NethMap 2003 was the first epidemiological report with information about consumption of antimicrobial agents and antimicrobial resistance among medically important bacteria in the Netherlands. It was presented in April 2003 during the SWAB symposium 2003 [2]. NethMap was named after a similar yearly report from Denmark (DANMAP). In contrast to the DANMAP report, veterinary data in the Netherlands are published in separate reports, called MARAN (http://www.cvi.wur.nl/NL/publicaties/rapporten/ maranrapportage/).

From 2003 through 2008 NethMap has been updated annually, and can be downloaded from http://www.swab.nl $>$ professional>NethMap. NethMap is published by SWAB in collaboration with the RIVM. Data on delivery of antimicrobials from hospital pharmacies are collected by SWAB (Figure 1), and data from $90 \%$ of all community pharmacies are provided by the Foundation for Pharmaceutical Statistics (Figure 2). Data on antimicrobial resistance in hospitals are collected from local laboratories by RIVM. The susceptibility of strains collected from outpatients and hospital departments (Urology, Pulmonology and Intensive Care) is determined quantitatively by the Laboratory of Medical Microbiology of Maastricht University. The population coverage for the resistance surveillance programmes is approximately $30 \%$.

Over the past decade, outpatient consumption of antibiotics has risen only slightly, from 9.9 to 11.1 defined daily doses 
(DDD)/1,000 inhabitants/day. In hospitals overall antibiotic use increased significantly from 47.8 to 62.2 DDD per 100 patientdays, but this increase was due to the steady reduction in the average length of patient hospital stays. Overall antibiotic use per 100 admitted patients remained constant. Outside hospitals, coamoxiclav gradually replaced amoxicillin (Figure 3) and, according to revised guidelines for general practitioners (GPs) for the treatment of cystitis, more nitrofurantoin was used at the expense of trimethoprim. The percentage of Streptococcus pneumoniae which was of intermediate susceptibility or resistant to penicillin and the percentage of Staphylococcus aureus resistant to oxacillin (MRSA) remained lower than 3\%, but resistance of $S$. pneumoniae

\section{F I G U R E}

Distribution of antibiotics administered for systemic use ${ }^{\star}$ (defined daily doses (DDD)/1,000 inhabitants/day) in primary health care, the Netherlands 2007

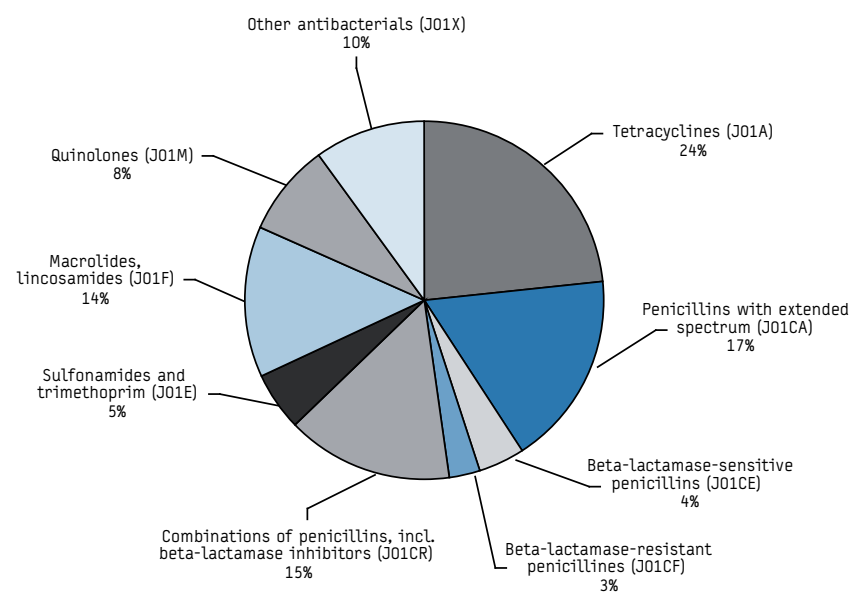

Source: Stichting Farmaceutische Kengetallen - SFK.

* Anatomical Therapeutic Chemical (ATC) Classification System J01

\section{F I G U R E 3}

Use of amoxicillin and co-amoxiclav in primary health care, the Netherlands $1998-2007$

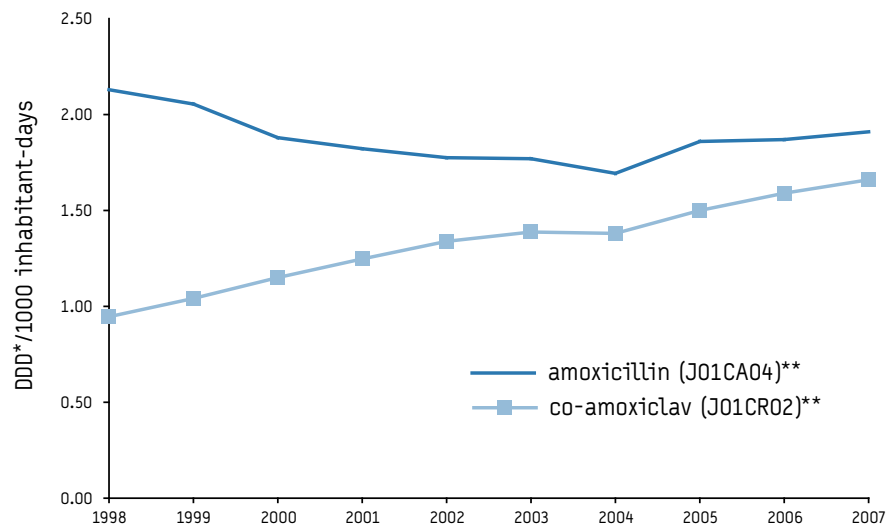

and S. aureus to macrolides has increased to nearly $10 \%$ of the investigated isolates. Escherichia coli resistance to ciprofloxacin among hospitalised patients increased to 9\% in 2007 (Figure 4). Occasionally, hospital epidemics of Klebsiella pneumoniae resistant to third-generation cephalosporins occurred, but the overall percentage of such strains remained low at 3-6\%. In contrast, the ciprofloxacin resistance in Neisseria gonorrhoeae from sexually transmitted diseases' (STD) clinics has increased to such a high level (44\%) that fluoroquinolones cannot be advised anymore for first-line treatment. The Dutch guidelines for treating gonorrhoea have been adapted accordingly.

\footnotetext{
F I G U R E 2
}

Distribution of antibiotics administered for systemic use ${ }^{\star}$ (Defined Daily Doses (DDD)/100 patient-days) in hospitals, the Netherlands, 2006

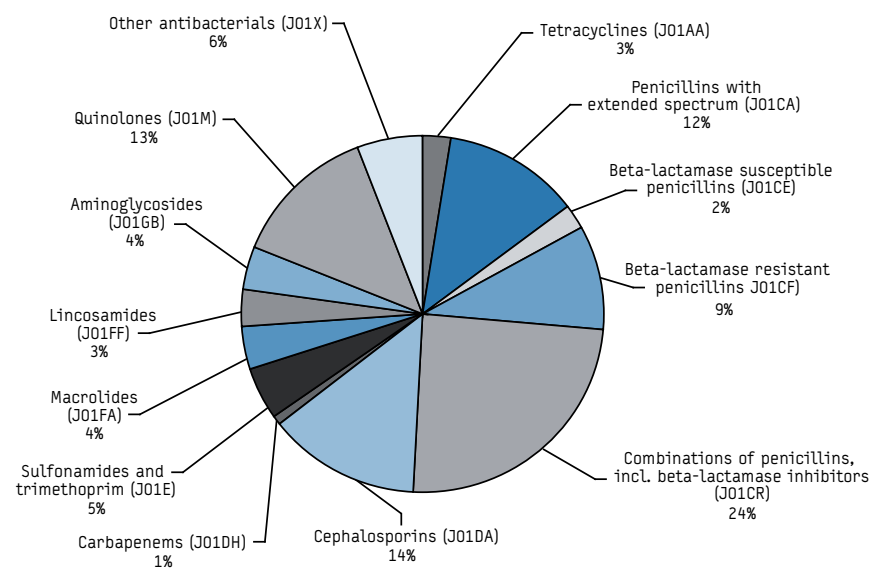

Source: Dutch Working Party on Antibiotic Policy - SWAB.

* Anatomical Therapeutic Chemical (ATC) Classification System J01

Source: Stichting Farmaceutische Kengetallen - SFK.

** Anatomical Therapeutic Chemical (ATC) classification code

\section{F I G U R E 4}

Trends in resistance to antibiotics among Escherichia coli from unselected hospital departments, the Netherlands, 1996-2007

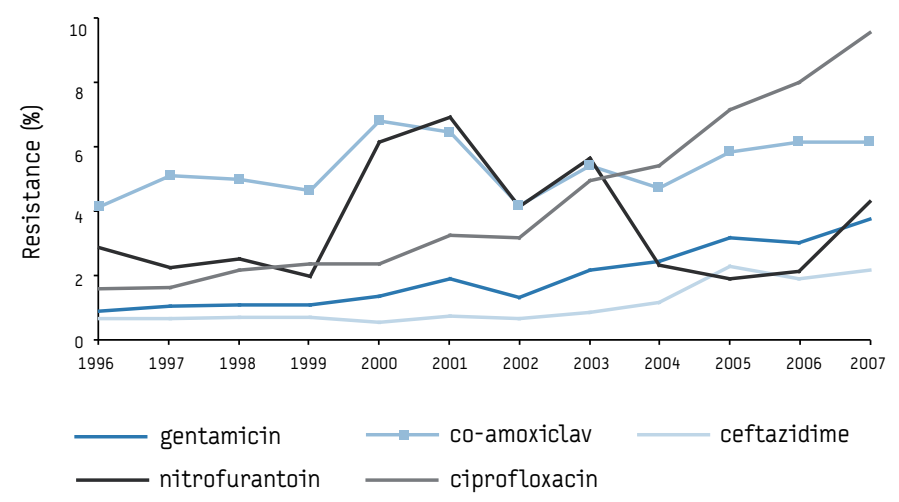


Guideline development in the Netherlands

Since the late 1980s, the Dutch College for General Practitioners has been running a guideline programme. Guidelines have been developed for e.g. otitis media in children, sinusitis, sore throat and pneumonia. These guidelines are regularly updated. In addition, the GPs have in place a "peer review group" system: a nationwide structure of general practitioners' peer review groups, with collaborating pharmacists, which aims to promote rational prescribing through audit and feedback [3].

Since its conception, SWAB has developed national guidelines for the use of antibiotics, which are aimed at the hospitalised adult patient. Initially, the draft guidelines were prepared by a writing committee, selected by SWAB, consisting of five to ten experts: medical microbiologists, infectious diseases' specialists, hospital pharmacists and medical specialists relevant to the specific topic. After review by another 25 experts, the guidelines were finalised and published. Guidelines were published in the major national Dutch medical journal (Nederlands Tijdschrift voor Geneeskunde) [4].

In 2001, a survey among hospital antibiotic policy committees revealed that the majority of respondents were aware of SWAB guidelines, but it was suggested that the draft guidelines should be made more broadly available, e.g. on the internet, and with a clearer method for grading the strength of the evidence on which the guideline was based. A particular feature of infectious diseases' guidelines is that local epidemiology and resistance data must be taken into account, and NethMap has provided this information since 2003. As a result of our survey and following the principles of evidence-based guideline development [5] we revised the procedures for the development of SWAB guidelines in $2005[6,7]$. The new procedure includes the consultation of the concerned professional societies for delegating experts to the writing committee, and all their members are given an opportunity to comment on draft guidelines. There are now also GPs on the writing committee to ensure that there is consistency between the guidelines for ambulatory care and hospitals. After final approval by the board, SWAB guidelines are posted on the SWAB website (www. swab.nl). For most of the guidelines English versions are freely available from the internet. Implementation of the guidelines in hospitals is studied by government-funded research projects [8].

\section{The national electronic antibiotic guide 'SWAB-ID' for use in} hospitals

The survey (unpublished data) among Dutch hospital antibiotic policy committees also revealed their wish to compile a comprehensive, national antibiotic treatment guide. SWAB took up this challenge, and in 2006 we introduced our electronic national antibiotic guide 'SWAB-ID' for the antibiotic treatment and prophylaxis of common infectious diseases in hospitals [9]. This guide also contains a formulary for all antimicrobial drugs available in the Netherlands. Treatment choices and dose regimens are based on existing national evidence-based guidelines, where available. Where no guideline is available, the advice is based on an inventory of the antibiotic policies of the 12 Dutch centres with an infectious diseases' or medical microbiology training programme. The national antibiotic guide can be accessed through the SWAB website (http://customid.duhs.duke.edu/NL/Main/Start.asp) and can also be downloaded on PDA/PocketPC, free of charge. The guide is updated regularly, for instance when new guidelines are issued or new antimicrobial agents become available.
Every hospital antibiotic policy committee in the Netherlands is offered the opportunity to edit the national version for local use. For a relatively small fee, SWAB provides a copy of the national version, in which adaptations can be made if local circumstances so demand, and this local version is again accessible through the internet, and downloadable on PDA. So far, six out of eight university hospitals, and ten non-academic hospitals / hospital groups are now using a local version of the national SWAB guide.

SWAB, Europe, and the First European Antibiotic Awareness Day

SWAB assisted Croatia in implementing EU directives and recommendations in the field of antimicrobial resistance and the sound use of antibiotics within a framework project launched by the Dutch Ministry of Foreign Affairs in 2006 [10]. Although antibiotic use and resistance rates in the Netherlands are relatively low compared to almost any other country [11], the NethMap surveillance 2008 report shows that figures are rising slowly. The reasons for this are not fully understood. Up to now, SWAB initiatives to maintain prudent antibiotic use have addressed healthcare professionals only. The Council document [1] included recommendations to make consumers aware of the risks posed by antimicrobial resistance. In the spirit of the first European Antibiotic Awareness Day that will take place across Europe on 18 November 2008 [12], SWAB will soon develop activities to increase awareness among the general public of the importance of consolidating the prudent use of antibiotics.

\section{References}

1. Council of the European Union. Council Recommendation of 15 November 2001 on the prudent use of antimicrobial agents in human medicine. Official Journal of the European Union 2002 Feb. L 34/13. Available from: http://eurlex.europa.eu/LexUriServ/LexUriServ.do?uri=0J:L:2002:034:0013:0016:EN:PDF

2. Verbrugh HA. Mapping antibiotic use and resistance in the Netherlands: SWAB and NethMap. Neth J Med. 2003;61(11):341-2.

3. Coenen S, Kuyenhoven MM, Butler CC, Van Royen P, Verheij TJ. Variation in European antibiotic use. Lancet 2001;358(9289):1272.

4. Van Kasteren MEE, Wijnands WJA, Stobberingh EE, Janknegt R, Van der Meer JWM. [Optimaliseren van het antibioticabeleid in Nederland. II. SWABrichtlijnen voor antimicrobiële therapie bij thuis opgelopen pneumonie en bij nosocomiale pneumonie] Optimization of the antibiotics policy in the Netherlands. II. SWAB guidelines for the antimicrobial therapy of pneumonia in patients at home and as nosocomial infections. The Netherlands Antibiotic Policy Foundation. Ned Tijdschr Geneeskd. 1998;142(17):952-6.

5. The AGREE Collaboration. Writing Group: Cluzeau FA, Burgers JS, Brouwers M, Grol R, Mäkelä M, Littlejohns P, et al. Development and validation of an international appraisal instrument for assessing the quality of clinical practice guidelines: the AGREE project. Qual Saf Health Care. 2003;12:18-23.

6. Prins JM, Kullberg BJ, Gyssens IC. National guidelines for the use of antibiotics in hospitalised adult patients: the SWAB guidelines revisited. Neth J Med. 2005;63(8):288-90.

7. Schouten JA, Prins JM, Bonten MJ, Degener J, Janknegt RE, Hollander JM, et al; Dutch Working Party on Antibiotic Policy. Revised SWAB guidelines for antimicrobial therapy of community-acquired pneumonia. Neth $\mathrm{J}$ Med. 2005;63(8):323-35.

8. van Kasteren ME, Mannien J, Kullberg BJ, de Boer AS, Nagelkerke NJ, Ridderhof $M$, et al. Quality improvement of surgical prophylaxis in Dutch hospitals: evaluation of a multi-site intervention by time series analysis. J Antimicrob Chemother. 2005;56(6):1094-102.

9. van Vonderen MG, Gyssens IC, Hartwig NG, Kullberg BJ, Leverstein-van Hall MA Natsch $S$, et al. [Optimalisation of the antibiotic policy in The Netherlands. $X I$. The national electronic antibiotic guide 'SWAB-ID' for use in hospitals]. [In Dutch]. Ned Tijdschr Geneeskd. 2006;150(46):2560-4.

10. Dutch Ministry of Foreign Affairs. The Matra Programme. Available from: http:// www.minbuza.nl/en/themes,european-cooperation/the_matra_programme file

11. Goossens H, Ferech M, Vander Stichele R, Elseviers M; ESAC Project Group. Outpatient antibiotic use in Europe and association with resistance: a crossnational database study. Lancet. 2005;365(9459):579-87. 
12. European Antibiotic Awareness Day [homepage on the internet]. Stockholm: The European Centre for Disease Prevention and Control [cited 12 Nov 2008]. Available from: http://antibiotic.ecdc.europa.eu/default.asp

This article was published on 13 November 2008.

Citation style for this article: Prins JM, Degener JE, de Neeling AJ, Gyssens IC, the

SWAB board. Experiences with the Dutch Working Party on Antibiotic Policy (SWAB) Euro Surveill. 2008;13(46):pii=19037. Available online: http://www.eurosurveillance.org ViewArticle.aspx?ArticleId=19037 